\title{
Victor Hugo oder die andere „Verlobung in St. Domingo“
}

Mit Bernardin de Saint-Pierres Paul et Virginie haben wir uns mit dem ersten großen französischen Kolonialroman beschäftigt, also einem Text, der zum größten Teil in den Kolonien spielt, in diesem Falle auf der Insel Mauritius. Der nur wenige Jahre nach Abschluss der Haitianischen Revolution und der politischen Unabhängigkeit Haitis verfasste Erzähltext des Heinrich von Kleist hatte uns nach Westen auf die Antillen geführt, dabei aber nicht mehr in ein funktionierendes Kolonialsystem, sondern eines, das unter dem Ansturm der Entrechteten und Versklavten in sich zusammengebrochen war. Heinrich von Kleist siedelte das gesamte Geschehen auf der zweigeteilten Insel Hispaniola an. Eine Insel ist immer eine Kippfigur, denn sie ist stets Insel-Welt und Inselwelt zugleich. Einerseits ist sie als Insel-Welt eine Welt für sich, ist sich also selbst eine ganze Welt in ihrer Isolation, Abgeschlossenheit und Abgeschiedenheit; und andererseits ist sie eine Inselwelt, also eine Welt vielfältiger Relationen innerhalb einer Welt als Archipel, in welcher die Insel gleichsam den Kreuzungspunkt vieler miteinander in Verbindung stehender archipelischer und transarchipelischer Verbindungspunkte darstellt. ${ }^{1}$

So ist es gewiss kein Zufall, dass sich unser nächster französischer Text ebenfalls mit einer Insel beschäftigt. Sie liegt nicht wie bei Bernardin de SaintPierre in den „Indes orientales“ - wie man in Europa damals die Kolonien im Osten nannte -, sondern in jener neuen Welt, in welcher Chateaubriand seinen Roman Atala angesiedelt hatte und Kleist seine verdichtete Behandlung des haitianischen Revolutionsstoffes situierte. Wir wechseln also in die „Indes occidentales“, eine koloniale Bezeichnung, die Sie heute noch im englischen Terminus „West Indies“ finden können, der Teile der Karibik bezeichnet. Und wieder wird der Umsturz und die Sklavenrevolution auf den französischen Pflanzungen der reichen Kolonie Saint-Domingue Gegenstand sein, der damals unbestritten reichsten Kolonie der Welt, mit anderen Worten: der damals am schamlosesten ausgebeuteten Kolonie auf dem ganzen Planeten. Es geht im Folgenden um einen Text des jungen Victor Hugo, der sich damals mit diesem Thema auseinander-

1 Vgl. zur Archipelsituation am Beispiel Kubas Ette, Ottmar: Cuba: zwischen Insel-Welt und Inselwelt. Von der Raumgeschichte zur Bewegungsgeschichte. In: Ette, Ottmar / Wirth, Uwe (Hg.): Nach der Hybridität. Zukünfte der Kulturtheorie. Berlin: Verlag Walter Frey - edition tranvía 2014, S. 217-250; zur Archipel-Situation in autobiographischen Dimensionen vgl. ders.: Romanistik als Lust. Kleines romanistisches ABC. In: Ertler, Klaus-Dieter (Hg.): Romanistik als Passion. Sternstunden der neueren Fachgeschichte VII. Wien: LIT Verlag 2020, S. 165-189. 
setzte, das die Gemüter Ende des 18. und zu Beginn des 19. Jahrhunderts wie kein anderes in höchste Aufregung versetzte: Längst waren die Verhältnisse auf SaintDomingue oder Haiti zum Paradigma geworden.

Bevor wir uns aber diesem Roman genauer zuwenden, sollten wir uns mit einigen Biographemen aus dem Leben Victor Hugos beschäftigen, der am 26. Februar 1802 in Besançon geboren wurde und am 22. Mai 1885 hochgeehrt in Paris verstarb. Es ist nicht einfach, kurz das Leben dieses Giganten der Literatur zu resümieren, zumal sich Victor Hugo auch sehr erfolgreich als Politiker betätigte. Dabei zeigte er die eher seltene Eigenschaft, im Gegensatz zu den meisten Männern, die mit steigendem Alter immer konservativer und politisch ,rechter' werden, einen Werdegang einzuschlagen, der ihn von monarchistischen und erzreaktionären Positionen immer weiter nach links bis hin zu sozialistischen Ideen führen sollte, wobei er sich vehement für soziale Anliegen stark machte.

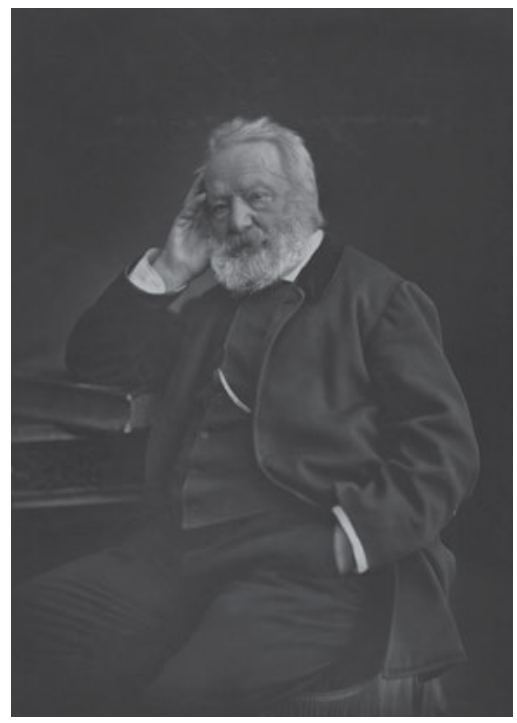

Abb. 22: Victor Hugo

(Besançon, 1802 - Paris, 1885).

Victor-Marie Vicomte Hugo kam als der jüngste von drei Söhnen eines später von Napoleon zum General beförderten und in den Adelsstand erhobenen Vaters sowie einer Mutter auf die Welt, die schon bald eine neue, außereheliche Beziehung einging und sich nicht sehr intensiv um ihre drei Söhne kümmerte. Der kleine Victor war schwach und kränklich und nichts zeigte an, dass er sehr robust ein langes Leben genießen sollte. Nach mehreren Wirrungen, Auseinandersetzungen zwischen den Eltern und Umzügen, die Victor aber niemals als störend erschienen, wurden die drei Söhne allesamt in einer Pariser Privatpension unter- 
gebracht und besuchten das berühmte Lycée Louis-le-Grand. Dort betätigte sich der junge Victor schon früh schriftstellerisch - eine Tatsache, die der peruanische Literaturnobelpreisträger Mario Vargas Llosa in einem Buch über Victor Hugo hervorhob, das ich Ihnen zur Lektüre empfehle. ${ }^{2}$ Von der Reise 1811 und 1812 nach Madrid zu seinem dort stationierten Vater sollte der Schriftsteller, der sich später selbst nach Spanien begab, ein lebendiges Andenken bewahren. Überhaupt sollte Victor Hugo von vielen seiner zahlreichen Reisen literarische Früchte ernten.

Ich hatte schon erwähnt, dass es laut einem Tagebucheintrag von 1816 das Ziel des jugendlichen Hugo war „Chateaubriand zu werden oder nichts“; und so reichte er 1817 eines seiner Gedichte bei einem Wettbewerb der Académie française ein, das den Preis auch erhalten hätte, hätte man nicht aufgrund des zarten Alters des Dichters an eine Täuschung geglaubt. Als Siebzehnjähriger gründete er zusammen mit seinen Brüdern eine Zeitschrift mit dem Titel Le Conservateur littéraire, die an Chateaubriands Periodikum Le Conservateur orientiert war. Für diese rechtskonservativ und romantisch ausgerichtete Zeitschrift schrieb Hugo unter verschiedenen Namen und Pseudonymen den größten Teil der Artikel und Beiträge. Als er im selben Jahr eine Auszeichnung in einem Dichterwettbewerb, den Jeux floraux von Toulouse, erhielt, knüpfte er Kontakte mit literarischen Zirkeln der französischen Hauptstadt und legte erste literarische Freundschaften an. Seine später in Buchform veröffentlichten Oden bescherten ihm erste Anerkennungen.

Nach dem Tod seiner Mutter heiratete Hugo seine ihm seit der Kindheit vertraute Jugendfreundin, ging jungfräulich wie sie in die Ehe und erfreute sich einer ungehemmten sexuellen Potenz, welche - wie Mario Vargas Llosa nicht zu betonen vergaß - seine Frau, die von ihm fünf Kinder gebar, überstrapazierte und über die Jahre ermüdete. Ob wir wie der peruanische Schriftsteller diese Potenz freilich mit Hugos literarischer Zeugungskraft in Verbindung bringen dürfen, entzieht sich unseren Einblicken. Tatsache aber war, dass der junge Dichter unaufhörlich schrieb und bereits früh eine Vielzahl von Gedichten veröffentlichen konnte. Für seine royalistischen Oden erhielt er eine staatliche Gratifikation und weitere Vergünstigungen, später auch die persönliche Einladung, an der Königsweihe von Charles X. teilzunehmen. Hugo gehörte zunehmend zum monarchistisch-revanchistischen Establishment.

2 Vgl. Vargas Llosa, Mario: La tentación de lo imposible: Victor Hugo y „Los Miserables“. Madrid: Santillana Editores 2004; sowie ders.: Briznas: Los Miserables. A ciento cincuenta años de su publicación. In: Interfolia (Monterrey, Nuevo León) IV, 13 (2012), S. 40-42. 
Auf dasselbe Jahr 1820 geht Hugos erstes erzählendes Prosawerk zurück, sein wohl seit 1817 entstehender Roman Bug-Jargal, der auf der Insel Hispaniola spielt. Hugo arbeitete diesen Text 1826 zu einem langen Roman mit vielfältigen Peripetien um, ein Debütroman, mit dem wir uns noch näher beschäftigen werden. $\mathrm{Zu}$ diesem Zeitpunkt war der Schriftsteller noch Royalist, doch sollte er bald unter dem Einfluss zahlreicher literarischer Freunde zum oppositionellen Liberalismus umschwenken. 1827 schrieb der Dichter das Theaterstück Cromwell, das weniger als solches als vielmehr durch seine berühmte Préface wirkte, das vielzitierte Vorwort, und spätestens zu diesem Zeitpunkt Hugo zum Sprachrohr der romantischen Schule avancieren ließ. Dem noch jungen romantischen Dichter wurden auch in dieser Lebensphase zusammen mit seinem Freund Lamartine, mit dem wir uns etwas später in der Vorlesung beschäftigen werden - zahlreiche Ehrungen zuteil.

Mit der Uraufführung seines Stücks Hernani am 25. Februar 1830 und der hitzigen Saalschlacht der „Bataille d’Hernani“ wurde Hugo endgültig zum Wortführer der französischen Romantik. Chateaubriand war spätestens jetzt überholt: Victor Hugo trat im literarischen Feld Frankreichs sein Erbe an. In rascher Folge erscheinen nun zentrale Werke, darunter 1831 sein sicherlich erfolgreichster und bis heute berühmtester Roman, Notre-Dame de Paris, der im Deutschen unter dem Titel Der Glöckner von Notre-Dame auch durch beliebte Verfilmungen nahezu Kultstatus genoss. Zwischen 1838 und 1840 unternahm Hugo drei Rhein-Reisen, die zu seinem dreibändigen Werk über den Rhein führen, wo er die deutsch-französische Zusammenarbeit evozierte und Ideen für eine künftige Europäische Union entwickelte, Ideen einer Gemeinschaft der „Vereinigten Staaten von Europa“, die erst hundert Jahre später realisiert werden sollten. ${ }^{3}$

Immer häufiger nahm Hugo politisch Stellung und setzte - wie etwa in Le Dernier Jour d'un Condamné - sein literarisches Schreiben gezielt etwa für den Kampf gegen die Todesstrafe ein. Victor Hugo avancierte zu einem der schlagkräftigsten und einflussreichsten Intellektuellen avant la lettre in Frankreich. Er wird in die Légion d'Honneur und - nach mehreren vergeblichen Versuchen - in die Académie française gewählt, 1845 ist er „Pair de France“. Sein Aufstieg als öffentliche Figur setzt sich ungebremst fort.

Mit diesem hohen symbolischen Kapital seiner Ernennungen und Mitgliedschaften ausgestattet, steigt Victor Hugo definitiv in die Politik ein und wird Abgeordneter für Paris in der Assemblée Constituante, später als konservativer Politiker in der Assemblée Législative. Er positioniert sich dort durch eine Rede

3 Vgl. hierzu das Hugo-Kapitel in Kraume, Anne: Das Europa der Literatur. Schriftsteller blicken auf einen Kontinent (1815-1945). Berlin - New York: Walter de Gruyter 2010. 
gegen den Prince-Président, ergreift für soziale Anliegen Partei und muss nach dem Staatsstreich vom 2. Dezember 1851, in dem sich Bonaparte zum Präsidenten auf Lebenszeit machte, ins Exil - zunächst nach Brüssel, dann auf die Insel Jersey, später auf die benachbarte Kanalinsel Guernesay. Als sich Napoleon III. zum Kaiser der Franzosen ausrufen lässt, erscheint Hugos legendäres Napoléon le Petit gegen „Napoleon den Kleinen“, das auf großen Widerhall stieß und Hugo in Frankreich wieder sehr präsent werden ließ.

Seine politischen Attacken blieben virulent, sein intellektueller wie sein literarischer Einfluss wurden außerordentlich. Es war, als wäre der Schriftsteller und Intellektuelle im Exil nochmals gewachsen. Er pfiff auf einen Amnestieerlass von Napoleon III. und blieb im Exil, von wo aus er sein literarisches Werk sowie seine politischen Stellungnahmen gut $\mathrm{zu}$ koordinieren vermochte. Mehr und mehr interessierte sich Hugo für soziale, politische und wirtschaftliche Probleme. 1861 schloss er seine Arbeit an Les Misérables ab, die im Folgejahr erschienen und mit ihren Sozialdarstellungen der ökonomisch und gesellschaftlich Ausgebeuteten bis heute faszinieren. War es, wie Vargas Llosa bereits im Titel seines Hugo-Bandes meinte, die Versuchung des Unmöglichen?

Wie auch immer man diese Frage beantworten mag, Victor Hugo blieb im Gedächtnis seiner französischen Leserschaft auch der Dichter der Contemplations oder der Chansons des rues et des bois, die keineswegs hinter seiner Prosa zurückstehen. Es waren nun nicht mehr einzelne Werke, die hervorstachen, sondern ein gesamtes Werk aus Essays und Gedichten, aus Romanen und Streitschriften, aus Theaterstücken und Reiseskizzen, das die Zeitgenossen in ihren Bann schlug. Doch selbst in der Prosa setzte Hugo noch einmal Zeichen: 1874 erschien sein vehementes Quatrevingt-treize über die „Terreur“ der Französischen Revolution. Sein gesamtes Leben lang war der Schriftsteller aus Besançon ein politisch engagierter Autor, auch wenn sich seine Positionen im Laufe dieses langen Lebens erheblich wandelten. Als Victor Hugo 1885 starb, war er zu so etwas wie dem moralischen Gewissen Frankreichs geworden. Er hatte eine Bedeutung erreicht, wie sie in Deutschland allein Goethe zuteil geworden war. Angesichts dieser überragenden nationalen Bedeutung des Dichters wurde beschlossen, ihn im Panthéon beizusetzen und seinen Sarg unter dem Arc de Triomphe aufzubahren. Noch heute beeindrucken die Photographien der ungeheuren Menschenmengen, welche an den Trauerfeierlichkeiten in Paris teilnahmen. Der Tod des französischen Schriftstellers geriet zu einer wahren Apotheose. So viel also zum wahrhaft beeindruckenden Leben des Victor Hugo. Doch wenden wir uns nun seinem Debütroman zu, der über sechs Jahrzehnte zuvor entstand! 


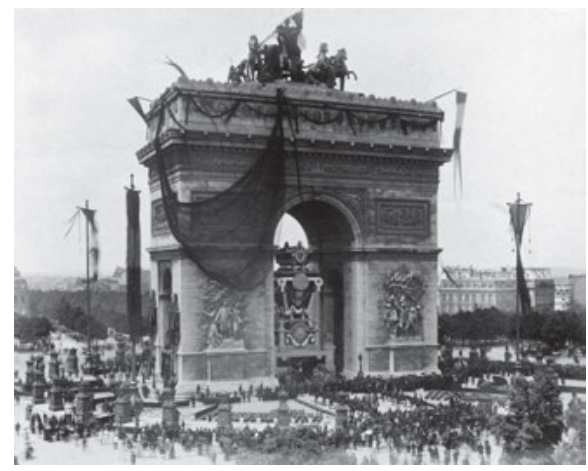

Abb. 23: Trauerfeierlichkeiten für Victor Hugo am 31. Mai 1885.

Dieser Roman imponiert zunächst durch die spezifische Sprache des noch sehr jungen und reaktionär ausgerichteten Schriftstellers, der seine dichterischen Kompetenzen nun auf die erzählerische Schöpfung ausweitete. Dabei handelt es sich um eine Sprache, welche nicht zuletzt bestimmte Spezifika des Französischen vor Ort auf den Antillen sowie die sprachliche Einbettung dieses Französischen in einem kreolischen Kontext berücksichtigt. Intertextuell gesehen - also mit Blick auf die Beziehungen zu anderen literarischen Bezugstexten anderer Autoren befinden wir uns freilich noch immer im Bereich einer internen Relationalität monolingualen Zuschnitts. Ich verstehe darunter Beziehungen zwischen Literaturen, die in derselben romanischen Sprache abgefasst sind, auch wenn diese Sprache unterschiedliche Varietäten aufweist und diese ganz selbstverständlich auch sichtbar macht.

So weist der Romantext, um den es hier geht, bereits sprachlich einige Besonderheiten auf, bezieht Victor Hugo zum Teil doch auch Sätze und Ausrufe im „français créole“ sowie auf Spanisch mit in seinen Roman ein - vor allem in der Absicht, die Ansiedlung des Geschehens an einem anderen Ort sprachlich beziehungsweise logosphärisch vor Augen und Ohren zu führen. Denn die reiche französische Kolonie Saint-Domingue war nur auf offizieller Ebene ein französischsprachiges Territorium: Die weit überwiegende Mehrzahl der Bewohner damals also die Sklaven innerhalb des ausbeuterischen Kolonialsystems der Plantagenwirtschaft - sprachen kein Französisch, sondern eine sich rasch entwickelnde Kreolsprache, eben das „français créole“ dieses Teils der Antilleninsel. Insoweit ist die monolinguale Situation in diesem Roman durchaus teilweise auf komplexere interlinguale Strukturen und Beziehungen hin geöffnet, welche wir in unsere Analyse miteinbeziehen müssen.

Beschäftigen wir uns nun näher mit dem ersten Roman aus der Feder von Victor Hugo, der 1826 unter dem definitiven Titel Bug-Jargal erschien! Die Geschichte dieses Romans ist durchaus sonderbar, wie Victor Hugo in 
seinem auf den 24. März 1832 datierten zweiten Vorwort zur Neuausgabe selbst präzisierte:

1818 war der Autor dieses Buches sechzehn Jahre alt; er wettete, dass er innerhalb von vierzehn Tagen einen Band schreiben könnte. Und er verfasste Bug-Jargal. Sechzehn Jahre ist ein Alter, in dem man auf alles wettet und alles improvisiert.

Dieses Buch wurde folglich zwei Jahre vor Han d'Islande geschrieben. Und obwohl der Autor sieben Jahre später, im Jahre 1825, das Werk zum großen Teil umbaute und neu schrieb, so ist es gleichwohl durch seinen Hintergrund wie durch viele Details das erste Werk dieses Autors. [...] Und wie jene Reisende, welche sich in der Mitte ihres Weges umdrehen und noch in den nebligsten Falten des Horizontes den Ort zu finden suchen, von dem aus sie aufgebrochen sind, wollte der Autor seinerseits hier eine Erinnerung an jene Epoche voller Heiterkeit, voller Kühnheit und voller Selbstvertrauen festhalten, in welcher er frontal einen derart weiten Gegenstand anging, die Revolte der Schwarzen auf Saint-Domingue im Jahre 1791, einen Kampf der Giganten und dreier Welten, die an dieser Frage beteiligt waren, nämlich Europa und Afrika als miteinander Kämpfende und Amerika als Schlachtfeld. ${ }^{4}$

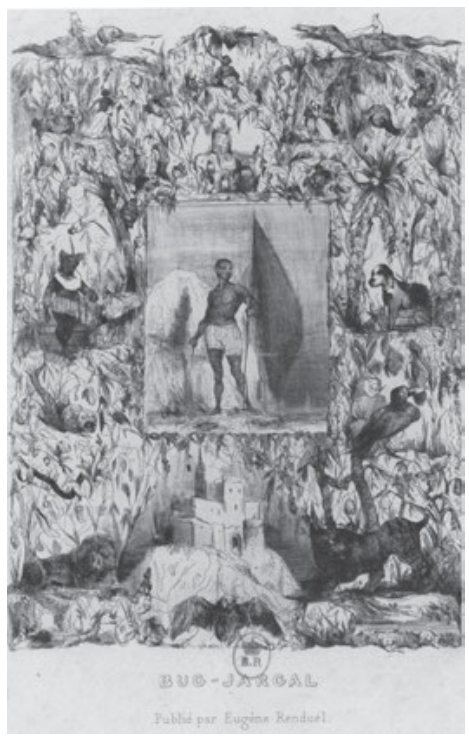

Abb. 24: Frontispiz des Romans Bug-Jargal, Radierung von Célestin Nanteuil, 1832.

In diesem Vorwort macht Victor Hugo sowohl auf die Entstehung seines ersten Romans im zarten Alter von sechzehn Jahren aufmerksam als auch auf die wiederholten Überarbeitungen, die freilich den Charakter dieses Textes als Frühwerk

4 Hugo, Victor: Bug-Jargal. Berlin: W. Natorff et Compagnie 1836, Préface vom 24 März 1832, s.p. 
nicht grundlegend verändert haben. Der gewählte Gegenstand, so Hugo, war gewaltig und in seinen Dimensionen eher furchteinflößend - nicht aber für den jungen Mann von sechzehn Jahren, der vor Selbstbewusstsein strotzte.

Victor Hugo spricht ausdrücklich von der Revolte, wir müssten heute sagen: von der Revolution auf Haiti - und er verhielt sich damit ein wenig so, wie sich Ludwig XVI. verhielt, als er noch am 14. Juli 1789 in seinem Tagebuch notierte: „Aujourd'hui, rien“, heute nichts. Am Tag der Französischen Revolution, des Sturms auf die Bastille, fand der damals noch amtierende französische König, dass es nichts Bemerkenswertes zu notieren gebe. Bisweilen sind die Herrschenden blind für die Veränderungen, die allenthalben um sie herum doch sichtbar sind. Ist dies die Ruhe im Auge des Hurrikans?

Nun, der französische König musste sich von seinen Zeitgenossen nur allzu rasch korrigieren lassen, dass nämlich das, was da in den Straßen von Paris vor sich ging, längst keine Revolte, sondern eine ausgewachsene Revolution war. Victor Hugo unterschied sich freilich von seinen französischen Zeitgenossen kaum, die ebenfalls im ,Aufstand“ einiger schwarzer Sklaven auf einer fernen Insel im Meer der Antillen keinerlei Revolution erkennen mochten. Noch eine Hannah Arendt sollte das traurigerweise so sehen.

Der Schriftsteller macht jedoch von Beginn an deutlich, dass es sich bei diesen Ereignissen um eine Art trikontinentale Dreiecksbeziehung handelte, eine Auseinandersetzung, an der Europa, Afrika und Amerika mit unterschiedlichen Interessenlagen beteiligt gewesen seien. Eine solche Sichtweise geht natürlich auf den Dreieckshandel zurück zwischen den drei Kontinenten, der den damals noch schwunghaften und grausamen Sklavenhandel befeuerte, sowie auf das, was man in den letzten Jahren im Kielwasser von Paul Gilroy den Black Atlantic genannt hat. ${ }^{5}$ Ob Afrika in Amerika dann immer noch getrennt voneinander als Afrika und Amerika zu bezeichnen sind und Amerika nichts weiter als den Schauplatz der Ereignisse bildet, darf aus heutiger kulturwissenschaftlicher Perspektive durchaus bezweifelt werden. Denn längst hatten die afrikanischen Sklaven in den Amerikas eigenkulturelle Entwicklungen genommen, welche eine spezifisch transkulturelle Dimension erreichten, mit der wir uns noch zu beschäftigen haben.

5 Vgl. hierzu Gilroy, Paul: The Black Atlantic. Modernity and Double Consciousness. London: Verso 1993; sowie Der Black Atlantic. Herausgegeben vom Haus der Kulturen der Welt in Zusammenarbeit mit Tina Campt und Paul Gilroy. Berlin: Haus der Kulturen der Welt 2004; zur Sklaverei insgesamt siehe Zeuske, Michael: Handbuch Geschichte der Sklaverei. Eine Globalgeschichte von den Anfängen bis zur Gegenwart. 2., überarbeitete und erweiterte Auflage. 2 Bände. Berlin Boston: Walter de Gruyter 2019. 
Doch offenkundig war im Zeichen rassistischer Vorstellungen eine solche Sichtweise der Dinge zu Beginn des 19. Jahrhunderts noch nicht möglich. Transkulturelle Dynamiken entfalteten sich zwar, konnten aber noch nicht adäquat gedacht werden. Wir wissen, dass die Zeitgenossen Hugos dies nicht anders sahen und selbst ein Alexander von Humboldt bei seinen Untersuchungen der Ereignisse von Saint-Domingue immer davon sprach, es seien die Afrikaner, die mit ihrem Aufstand erstmals das Joch der Sklaverei glücklich abgeschüttelt hätten. Haiti, so Humboldt, könne dereinst zum Zentrum einer Konföderation schwarzer afrikanischer Republiken im Bereich der Antillen werden. ${ }^{6}$ Dass es sich bei diesen Gruppen schwarzer Sklaven, die seit Beginn des 16. Jahrhunderts in der Karibik zwangsverschleppt zusammenlebten und komplexe kulturelle Beziehungsgeflechte entfalteten, längst um Amerikaner oder - wie wir heute sagen würden Afroamerikaner handelte, können wir für unsere Zwecke allerdings kurzfristig ausklammern.

Wichtig jedoch ist mir vor allem, dass Victor Hugo in seinem Vorwort zu BugJargal sehr wohl den globalen Kontext markiert, innerhalb dessen sich sein Roman situiert. Und er hat - jenseits der Liebesgeschichte, auf die der Roman als einen diskursiven Motor nicht verzichten konnte - just den Export eines bestimmten gesellschaftlichen Modells, einer gesellschaftlichen Erfahrung zum Thema, für die sich auch Bernardin de Saint-Pierre, nicht aber Chateaubriand oder der junge Hugo selbst interessierten: die Französische Revolution. Aus einer konservativen, ja reaktionären europäischen Perspektive musste die Haitianische Revolution nicht als Revolution, sondern schlicht als Störung und Unterbrechung eines als ,natürlich` angesehenen Wirtschaftssystems kolonialer Ausbeutung erscheinen. Sie war nur ein Aufruhr schwarzer Sklaven, eine vorübergehende Revolte, nichts weiter: Frankreich hoffte, zu einem späteren Zeitpunkt die Zügel wieder anziehen zu können und belegte die Teil-Insel mit schweren finanziellen Reparationsforderungen und Verpflichtungen, welche die junge Republik Haiti von Beginn an in große Schwierigkeiten brachten.

Victor Hugo wählte sicherlich nicht zufällig während der Zeit der Restauration in Frankreich ein kriegerisches Epos als Sujet für seinen Roman: Zu angefüllt war die Zeit mit militärischen Expansionen, Siegen und schließlich den Niederlagen der Franzosen im Zeitalter Napoleons, als dass dies nicht einen jungen Menschen zumindest hätte begeistern können. In Bug-Jargal jedoch wählte Victor

6 Vgl. hierzu auch Ette, Ottmar: Insel-Text und archipelisches Schreiben: Alexander von Humboldts „Isle de Cube, Antilles en général“. In: edition humboldt digital. Hg. von Ottmar Ette. Berlin: Berlin-Brandenburgische Akademie der Wissenschaften. Version 1 vom 10.5.2017. <URL: http://edition-humboldt.de/v1/H0016213>. 
Hugo ein höchst komplexes Thema aus einer unmittelbaren Vergangenheit, in dem es zumindest auf den ersten Blick keine heldenhafte Rolle Frankreichs zu besingen gab. Es war vielmehr ein Kampf um die reichste Kolonie der Franzosen entbrannt und ein höchst grausamer Krieg entfesselt worden, der nach der Unabhängigkeit der USA von ihrem kolonialen Mutterland England nun zum zweiten Mal die Unabhängigkeit auf dem amerikanischen Kontinent proklamieren sollte. In Saint-Domingue oder Haiti ging es freilich nicht allein um eine Überwindung des kolonialen Status, sondern zugleich um den Ausgang aus der Sklaverei, die gerade erst in Frankreich von der Convention - unter dem Druck der Société des Amis des Noirs - abgeschafft worden war.

Victor Hugo hat zweifellos auf historische Figuren der Haitianischen Revolution zurückgegriffen, insbesondere auf Georges Biassou, Jean-François Papillon und Dutty Boukman, um seinen Bug-Jargal zu schaffen. Sein Protagonist nimmt Züge all dieser historischen Persönlichkeiten in sich auf. Man kann um den Namen „Bug-Jargal“ streiten und etwa darauf verweisen, dass Bug-Jargal und Gibraltar dieselbe Struktur besitzen, ein Isomorphismus bei kleiner Abweichung, der den jungen Autor wohl inspirierte. Und in der Tat gibt es auch herkulische Züge bei Bug-Jargal, so dass Hugo wohl ganz bewusst auf die Säulen des Herkules bei der Namensfindung seines Helden zurückgegriffen haben dürfte und damit auch mythologische Einsprengsel in seinen schnell verfassten Debütroman einflossen.

Das Phantasmatische des Namens wird auch im Doppel von Bug-Jargal und Habibrah deutlich, wobei letzteres zugleich unübersehbar die Amerikas orientalisiert; auch der Name Habibrah weist eine fast vollständige Symmetrie auf, doch ein zusätzliches $r$ findet sich auch hier. So entfaltet sich jedenfalls eine Mythologie der beiden einander entgegengesetzten abendländischen und morgenländischen Zivilisationen, die nun auf einer Antilleninsel einander plötzlich gegenüberstehen. Bei seiner Orientalisierung greift der junge Dichter auf den Topos morgenländischer Grausamkeit zurück, welche bereits im Namen Habibrah angelegt ist. So sind die Namen der handelnden Figuren in diesem Roman gewiss nicht zufällig gewählt; auch der Name d'Auverney für den Erzähler der Rahmenerzählung und den Protagonisten der Binnenerzählung etwa stammt aus Hugos eigener Familie mütterlicherseits. Hugo arbeitete nach eigener Aussage schnell und borgte und besorgte sich, was er sich rasch und ohne größeren Aufwand verschaffen konnte.

Sein wichtigster intertextueller Bezugstext war laut Forschungsliteratur die Description de la partie française de l'île de Saint-Domingue, die der französische Dichter mit vielen klimatischen Ingredienzien und naturräumlichen Bedingungen einer Welt in Verbindung brachte, die er - anders als Bernardin de SaintPierre oder Chateaubriand, aber ebenso wenig wie Heinrich von Kleist - nicht aus eigener Anschauung kannte. Doch ihm waren die Naturbeschreibungen des 
Schöpfers von Paul et Virginie ebenso bekannt und vertraut wie jene des Autors von Atala oder René, so dass wir die von uns bereits behandelten Prosatexte sehr wohl als weitere französische Intertexte seines Romans benennen dürfen. Den Verfasser des Génie du Christianisme hatte der junge Hugo tief in sich aufgesogen. Denn die Beschreibungen tropischer Landschaften, welche der Autor von BugJargal stets an scharfen Kontrasten entlang aufbaut, sind noch sehr stark im Stile eines Chateaubriand abgefasst und damit in den Traditionen der frühen französischen Romantik modelliert.

Aber nicht allein im landschaftlichen, sondern auch im menschlichen und moralischen Bereich baut sich die Grundstruktur des Romans aus deutlich herausgearbeiteten Kontrasten auf. Die Erzählstruktur mit ihrer wechselseitigen Artikulation von Rahmenerzählung und Binnenerzählung ist uns zum größten Teil bereits bekannt: Erzähltechnisch gibt es in Bug-Jargal also nicht viel Neues zu berichten. In einer Pause des Krieges erzählen sich Offiziere in einem Zelt interessante Geschichten aus ihrem Leben. Erst auf Ebene der Binnenerzählung wird das Geheimnis preisgegeben, das die Gestalt und individuelle Persönlichkeit von Léopold d'Auverney und seine eigentümliche Beziehung zu seinem Faktotum wie zu seinem Hund Rask umgibt.

Dieser Léopold d’Auverney ist - so wird uns gleich zu Beginn des vierten von insgesamt achtundfünfzig durchnummerierten Kapiteln oder Abschnitten mitgeteilt - als junger Mann auf jenen westlichen Teil der Insel Hispaniola gekommen, der unter dem Namen Saint-Domingue damals von so enormer ökonomischer Wichtigkeit für Frankreich war. Zu jener Zeit war die Insel noch eine perfekt funktionierende Sklavenkolonie, die für sich Modellcharakter innerhalb eines ausbeuterischen Systems der Sklaverei beanspruchen konnte. Hier war das statistische Verhältnis von Weißen und Schwarzen auf die Spitze getrieben, genügten doch wenige Weiße, um eine radikale Versklavung, Unterdrückung und ständige Auspeitschungen als System aufrecht zu erhalten. Andere europäische Kolonialmächte blickten neidisch auf diese kolonialistisch durchorganisierte Insel-Welt.

Léopold wird zu seinem Onkel geschickt, der eine riesige Zuckerrohrplantage besitzt und befehligt, ein wahres Hofleben mit genau geregelter Etikette hält, über Hunderte und Aberhunderte schwarzer Sklaven gebietet und eine schöne Tochter namens Marie besitzt, die Léopold d'Auverney ehelichen soll. Wunderbare Aussichten für den hübschen jungen Mann! Die Hochzeit der schönen Marie mit dem jungen Léopold wird jedoch durch zwei Tatsachen verzögert und schließlich verunmöglicht und damit beginnt die Handlung dieser Geschichte sich zu drehen: Erstens hat sie einen unbekannten schwarzen Verehrer, der anfangs unter dem Namen Pierrot, später dann unter Bug-Jargal hervortritt und über wahrlich herkulische Kräfte verfügt; und zweitens wird das Datum der geplanten Hochzeit just auf jenen Tag gelegt, an dem - wie Bug-Jargal weiß - der Aufstand der Sklaven 
in der französischen Kolonie losbrechen wird. Wir befinden uns also historiographisch gesehen in der ersten Phase der langen Haitianischen Revolution.

So kommt denn der unter einem Unstern stehende 22. August des Jahres 1791, an dem die beiden reichen und verliebten Weißen in der Kirche getraut werden. Es wird eine Trauung, auf die niemals mehr eine Hochzeitsnacht, eine Vereinigung der beiden Liebenden folgen wird, die diesen Bund fürs Leben beschließen könnte. Die Liebesgeschichte, die uns Victor Hugo erzählt, endet nicht weniger im Desaster als jene, die uns Bernardin de Saint-Pierre aus Mauritius oder Chateaubriand von den Ufern des Mississippi erzählte. Und jeweils steht am Ausgang all dieser Geschichten die Leiche einer schönen jungen Frau. In der Kolonie Saint-Domingue und auf der Plantage des Onkels zirkuliert just am Tag der Eheschließung erstmals der mit Respekt ausgesprochene Name des anfänglichen Gegenspielers und Rivalen um die Liebe Maries, zugleich aber des ,Edlen Wilden' und Mithelfers von d'Auverney: Bug-Jargal. Der unterscheidet sich so vorteilhaft von den Horden unkultivierter und grausamer schwarzer Sklaven, welche Hugo ein ums andere Mal blutrünstig an seiner Leserschaft vorbeidefilieren lässt.

Die ersten Berichte des Gouverneurs der Insel, welcher der Assemblée der Weißen von den Vorfällen berichtet, lassen keinen Zweifel an der Grausamkeit der Sklaven. Nicht die unmenschlichen Kolonialherren und Sklavenbesitzer der Insel, sondern ihre schwarzen Untertanen und Opfer werden aus diesem Blickwinkel zu rücksichtslosen Mordmaschinen stilisiert. Damit erscheint eine Sicht auf die Ereignisse und eine ,weiße Perspektive‘, die wie zu Beginn von Kleists Die Verlobung von St. Domingo eingenommen wird und im damaligen Europa dominierte. Es sind im Grunde Bilder der französischen „Terreur“, aus deren reichem Bilderschatz Victor Hugo sich bedient, um die Revolte der Schwarzen, die gegen ihre grausame Versklavung aufstehen, anschaulich werden zu lassen. Vernehmen wir die Worte des französischen Gouverneurs:

Hier sind die Berichte, die mir zugegangen sind. Die Revolte begann in dieser Nacht um 10 Uhr abends unter den Negern der Pflanzung Turpin. Die von einem englischen Neger namens Boukman befehligten Sklaven haben die Werkstätten der Pflanzungen Clément, Trémès, Flaville und Noé mit sich gerissen. Sie haben alle Plantagen in Brand gesetzt und Kolonisten mit unerhörter Grausamkeit massakriert. Ich werde Ihnen die ganzen Schrecknisse anhand eines einzigen Details zu verstehen geben. Ihre Standarte ist die Leiche eines Kindes, das am Ende einer Pike aufgespießt ist.

Ein Erschaudern unterbrach Herrn von Blanchelande.

- Das ist, was sich da draußen abspielt, fügte er hinzu. Drinnen ist alles umgestürzt. Mehrere Bewohner des Kaps haben ihre Sklaven getötet; die Angst hat sie grausam gemacht. Die Sanftesten oder die Wackersten haben sich darauf beschränkt, sie gut verschlossen einzusperren. Die Petits Blancs, die Weißen mit Kleinbesitz, klagen dieser Desaster die Freien von gemischtem Blute an. Mehrere Mulatten wären beinahe zu Opfern der Volkswut gewor- 
den. Ich habe ihnen als Asyl eine Kirche gegeben, die von einem Bataillon bewacht wird. Um zu beweisen, dass sie nicht mit den revoltierenden Schwarzen im Einvernehmen stehen, ließen die Mulatten mich bitten, ihnen zur Verteidigung einen Posten und Waffen zu geben. ${ }^{7}$

Wie Sie sehen, greift Victor Hugo in dieser Passage auf geschichtliche Fakten zurück und verwendet die historisch korrekten Namen von aus der Geschichte der Haitianischen Revolution bekannten Figuren wie Boukman oder Blanchelande. Wir haben es folglich mit einem Roman zu tun, der sehr wohl Züge eines historischen Romans nach dem Vorbild Walter Scotts trägt, wobei gerade die großen Gestalten historische Namen tragen, während die kleineren Romanfiguren fiktional sind und ,erfunden' wurden. Diese ,kleineren' Figuren werden freilich zu den eigentlichen Protagonisten der Geschichte, während die ,großen` Gestalten die Haupthandlung bestimmen.

Allerdings dominieren von Beginn an Position und Perspektive der Weißen, die kaum über die eigene Brutalität sprechen, im Notfall aber ihre Grausamkeit wie im obigen Zitat - auf jene der schwarzen Sklaven und die Angst vor ihren Missetaten zurückführen. Die aufständischen schwarzen Sklaven gingen mit so ungeheurer Bestialität gegen alle Weißen vor, würden alles, was sich ihnen in den Weg stelle, massakrieren und die Felder wie jeglichen Besitz der Weißen in Flammen und Rauch aufgehen lassen. Die an Lanzen und Piken aufgespießten Köpfe sind zweifellos ebenfalls historisch, bilden in gewisser Weise aber eine Reminiszenz an Vorfälle, die sich seit Beginn der Französischen Revolution in Paris ereigneten und nun auf Haiti übertragen wurden. Die bestialischen Handlungsweisen und Massaker der Weißen an ihren Sklaven werden hingegen entweder gar nicht oder nur am Rande vermerkt. Der gesamte Diskurs des Herrn de Blanchelande ist in ein legalistisches Spiel der Ausgeglichenheit zwischen den Massakern der Schwarzen, den Gegenaktionen der Weißen und den Ängsten der freien Mulatten getaucht, so dass das staatstragende Element dieser Erzählweise bestimmter Fakten fraglos beim französischen Gouverneur liegt.

Die Geschichte der Insel Hispaniola gehört zu den spannendsten und lehrreichsten Geschichten der Kolonialzeit schlechthin. Ich kann an dieser Stelle aber weder auf die erste europäische Entdeckung der von den Eingeborenen „Haiti“ genannten Insel Española 1492 durch Christoph Kolumbus noch auf die lange spanische Kolonialzeit oder die häufigen Überfälle durch Piraten, darunter auch durch den gefürchteten Briten Francis Drake, eingehen. Im Kampf zwischen den europäischen Kolonialmächten versuchten die Franzosen nach der ersten Phase beschleunigter Globalisierung unentwegt, aber zumeist ohne durchschlagenden

7 Hugo, Victor: Bug-Jargal, S. 64. 
Erfolg, auch ein Stück vom kolonialen Kuchen abzubekommen. Dies gelang im Bereich der Karibik erstmals mit der Inbesitznahme einer kleinen Insel namens „Tortuga“ vor der Küste Hispaniolas (französisch „La Tortue“, die gefürchtete Pirateninsel, die später zum Zentrum eines Reichs der Piraterie avancierte) und dann 1665 mit den von dort aus gestarteten Angriffen auf den Westteil Hispaniolas. Diesen erklärten die Franzosen einseitig für von Spanien unabhängig, um ihn ihrem eigenen, in Entstehung begriffenen Kolonialreich einzuverleiben.

Im Jahr 1685 - also gut hundert Jahre vor der Französischen Revolution - trat auf den Westindischen Inseln der berüchtigte Code Noir in Kraft, der die Grundregeln der Sklaverei im französischen Kolonialreich festlegte und überregionale Bedeutung erhielt. 1697 schließlich wurde der Westteil der Insel Hispaniola im Frieden von Rijswijk tatsächlich legaler Besitz Frankreichs unter dem Namen „Saint-Domingue“. Damit begann ein rasanter wirtschaftlicher Aufstieg, denn mit der Einwanderung französischer Kolonisten, der massiven Einfuhr schwarzer Sklaven aus Afrika und der enormen Ausweitung landwirtschaftlicher Nutzflächen entwickelte sich das auf Zucker spezialisierte Saint-Domingue zur reichsten und modernsten Kolonie überhaupt. Auf dieser intensiv kapitalistisch genutzten Teil-Insel wurde jener Zucker produziert, der einen großen Teil des europäischen Marktes abdeckte. Saint-Domingue wurde sozusagen zum Schaufenster der höchsten Rendite, die sich im Sklavenhandel und mit der Sklaverei-Wirtschaft kolonial erzielen ließ.

Setzen wir unseren kurzen historischen Rückblick fort: ${ }^{8} 1788$, also gerade einmal ein Jahr vor dem Ausbruch der Revolution, wurde in Paris das Comité Colonial, eine Interessenvertretung weißer Pflanzer, gegründet. Beim Tiers-Etat wurde zügig eine Zulassung von Deputierten aus Saint-Domingue erwirkt. Im selben Jahr 1788 aber erfolgte ebenfalls die Gründung der abolitionistischen, also für die Abschaffung der Sklaverei eintretenden Société des Amis des Noirs. Als die Französische Revolution am 20. August 1789 die Menschenrechte erklärte, fühlten sich zunächst die weißen Kreolen in ihren Autonomieabsichten bestärkt. Die Französische Revolution hatte gleichsam von Beginn an eine weit über Europa hinausweisende Schlagkraft, die allerdings - und daran war weniger zu denken - recht bald auch einen Vorbildcharakter dieser Revolution für andere Revolutionen antikolonialistischen Zuschnitts mitbedingte. Aber wer dachte bei dieser Erklärung der Menschenrechte durch freie weiße Franzosen schon daran, dass die schwarzen Sklaven sie auch auf sich selber beziehen würden?

8 Zur weiteren Lektüre sei empfohlen Bernecker, Walther L.: Kleine Geschichte Haitis. Frankfurt am Main: Suhrkamp 1994. 
Es geht mir an dieser Stelle unserer Vorlesung nicht darum, Ihnen die Ereignisse der Haitianischen Revolution nahezubringen, die wirklich zum Spannendsten in der Geschichtswissenschaft gehören und 1804 in die Anerkennung jenes Staates mündeten, der nach den USA der erste Staat im Süden Amerikas und weltweit das erste Beispiel einer erfolgreichen Sklavenrevolution darstellen sollte. Im Mai 1791 verfügte die Constituante in Paris die rechtliche Gleichstellung aller freien „gens de couleur“ in den französischen Kolonien: Noch schienen die weltpolitischen Auswirkungen überschaubar.

Dann aber begann am 22. August 1791 der bereits erwähnte Sklavenaufstand im Norden Haitis, aus dem sich die Haitianische Revolution entwickeln sollte. Die große, charismatische Figur dieses Beginns der Revolution, die über ein Jahrzehnt lang die vormals reiche Kolonie verwüsten und einen hohen Blutzoll verlangen sollte, war ohne jeden Zweifel Boukmann. Schon im September 1791 wurde das Gleichstellungsdekret des Mutterlandes wieder aufgehoben, jedoch im folgenden April erneut in Kraft gesetzt. Im September 1792 trafen dann drei jakobinische Kommissare in Saint-Domingue ein. Ein knappes Jahr später, im August 1793, sollten sie die vermeintlich definitive Aufhebung der Sklaverei verkünden. Doch bereits am 4. Februar 1794 wurde erneut die Sklaverei durch den französischen Konvent beschlossen. Während dieser gesamten Zeit der Beschlüsse und ihrer Rücknahmen aber brodelte es auf der französischen Zuckerinsel in ihrem noch zu Frankreich gehörenden Teil.

Die weitere Entwicklung der Haitianischen Revolution ist mehr oder minder bekannt. Eine der großen Figuren der Revolution, General Toussaint-L’Ouverture, von dem wir bereits im Zusammenhang mit Heinrich von Kleist hörten, dass er später jämmerlich in einem Gefängnis im französischen Jura, der Forteresse de Joux, frierend und einsam zu Grunde gehen sollte, wird 1797 zum starken Mann in Saint-Domingue. Er übersteht den inzwischen ausgebrochenen Bürgerkrieg zwischen Schwarzen und Mulatten und kann 1801 seine Herrschaft auch auf den größeren spanischen Ostteil der Insel ausdehnen. Dergestalt beginnen die traumatischen Erfahrungen der beiden ungleichen Inselhälften mit- und untereinander, die selbst in der aktuellen Gegenwart im Verhältnis zwischen Haiti und der República Dominicana noch immer nicht vergessen sind.

1802 versucht Frankreich, nun unter Napoleon, ein letztes, aber massives Mal, die abtrünnige Insel und Kolonie wieder unter seine Herrschaft zu zwingen und entsendet ein gewaltiges Expeditionsheer unter General Leclerc. Die Sklaverei wird wieder eingeführt, Toussaint-L'Ouverture verraten und nach Frankreich deportiert. Doch 1803 erleidet dieses Expeditionsheer der Franzosen, das längst durch Krankheiten wie das Gelbfieber dezimiert ist, eine vernichtende Niederlage. Jetzt ist der Weg frei für die Unabhängigkeit Haitis, dessen erster Präsident von 1804 bis 1806 Dessalines wird, der sich in der Folge zum Kaiser Jacques I. krönen 
lässt. 1806 kommt es zu Kämpfen zwischen den Mulatten unter Pétion einerseits und den Schwarzen unter General Henri Christophe, der durch die Errichtung einer prunkvollen Schlossanlage namens Sanssouci - da horcht man in Potsdam auf! - in die Geschichte einging.

Doch die mit all diesen Wirren und Wendungen verbundenen Geschicke können wir an dieser Stelle nicht weiterverfolgen. Das erste Land Lateinamerikas - ja, Haiti zählt hierzu, insofern die hier gesprochenen Sprachen des Französischen und des „français créole“ sich vom Lateinischen herleiten - und damit jenes Land, das einst die reichste Kolonie nicht nur der französischen Kolonialgebiete, sondern der gesamten kolonialen Welt war, tritt seinen Zug in jene Vierte Welt an, in der Haiti längst in der Falle sitzt. Doch die Sklavenrevolution auf der Insel hat seither nicht aufgehört, wie zu Zeiten Victor Hugos die Gemüter zu erhitzen und die unterschiedlichsten Wissenschaften zu beschäftigen.

Das oftmals überraschende Wechselspiel zwischen den Ereignissen in Frankreich und jenen in seiner reichsten Kolonie, zwischen der Französischen und der Haitianischen Revolution, wird des Öfteren auch in Bug-Jargal thematisiert. So hört der junge Léopold d'Auverney, der als Ich-Erzähler in der Binnenerzählung fungiert, von einem alten Soldaten das Folgende, wäre der doch zu einem monarchistischen Durchgreifen bereit:

Es sind die Schönredner und Advokaten, die alles verderben, hier wie im Mutterland. Hätte ich die Ehre, der kommandierende General des Königs zu sein, würde ich diese ganze Canaille vor die Türe werfen. Ich würde sagen: Der König regiert, und ich regiere. Ich würde die Verantwortung im Angesicht dieser sogenannten Repräsentanten allen Teufeln geben; Und mit zwölf Kreuzen des Heiligen Ludwig, die im Namen Ihrer Majestät versprochen wären, würde ich alle Rebellen auf die Ile de la Tortue hinaus fegen, die ehemals von Briganten wie diesen, von Freibeutern, bewohnt war. Erinnern Sie sich an das, was ich Ihnen sage, junger Mann. die Philosophen haben die Philanthropen gezeugt, welche ihrerseits die Negrophilen hervorbrachten, welche die Weißenfresser schufen, für die man noch einen griechischen oder lateinischen Namen finden wird. Diese vorgeblich liberalen Ideen, von denen man in Frankreich trunken ist, sind unter den Wendekreisen ein Gift. Man müsste die Neger mit Sanftmut behandeln, nicht zu einer sofortigen Freilassung aufrufen. Alle Schrecknisse, die Sie heute in Saint-Domingue sehen, sind aus dem Club Massiac entstanden, und der Sklavenaufstand ist nichts als der Gegenschlag zum Sturm auf die Bastille. ${ }^{9}$

In dieser Passage, die einer Romanfigur in den Mund gelegt ist, wird unverkennbar die These aufgestellt, dass letztlich alle Ereignisse in der weit von Paris entfernten Kolonie Saint-Domingue eine direkte Frucht der Ereignisse im französischen Mutterland sowie der Bestrebungen der Philosophen der Aufklärung sind, die sich

9 Hugo, Victor: Bug-Jargal, S. 69 f. 
für die Menschenrechte einsetzten. Lassen wir hier zunächst einmal außer Acht, dass sich diese ältere Romanfigur, die sich an den jungen Léopold richtet und die nicht der Erzähler ist, mit der frühesten Präsenz der Franzosen in der Karibik auseinandersetzt. Diese ließen sich auf der Insel Tortuga oder La Tortue als Bukaniers oder Freibeuter nieder und überfielen regelmäßig die Schiffe der mit Gold und Silber aus den Kolonien beladenen spanischen Schiffe. Der erfahrene Soldat tut dies vom Standpunkt einer gefestigten Kolonialmacht der Franzosen aus und verurteilt die damaligen Freibeuter, die freilich die Vormacht der Spanier untergruben und den Weg für die spätere Ausdehnung des französischen Kolonialsystems auf Teile der Karibik freimachten. So waren eben diese Freibeuter und Piraten der Beginn französischer Präsenz in der Karibik und insbesondere auf der großen Antilleninsel Hispaniola, die in ihren Anfängen letztlich nichts anderes als ein Beutegut französischer Piraterie gewesen war.

Lassen wir hier auch eher unerwähnt, dass die Äußerungen über den Club Massiac einen historischen Fehler des jungen Victor Hugo beleuchten, der seine Geschichtslektionen noch nicht vollständig gelernt hatte. Denn gemeint sind vielmehr die revolutionären Clubs und vor allem die bereits erwähnte Société des Amis des Noirs, die tatsächlich eine Freilassung und Befreiung aller Sklaven im französischen Einflussgebiet bereits im Jahr 1794 durchsetzte.

Entscheidend für unsere Fragestellung ist vielmehr, dass es hier ganz einfach um die Problematik geht, wie man mit den zahlreichen Sklaven in den französischen Kolonialgebieten umgehen sollte. Und diese altgediente Romanfigur plädiert ganz unverblümt gerade nicht für eine Freilassung der schwarzen Sklaven, sondern für eine ein wenig ,menschlichere‘ Behandlung, und zwar mit dem Ziel, die Sklaverei als Wirtschafts- und Kolonialsystem mit aller Kraft im Dienste des französischen Königs aufrechtzuerhalten - den es längst nicht mehr gab. Von dieser Position aus knüpfte er eine doppelte, von den Zeitgenossen in Frankreich, aber auch anderswo schon früh geteilte Verbindung. Diese „double articulation“ verlief wie folgt: Erstens ist die Französische Revolution eine unmittelbare Folge der Aufklärung, also letztlich ein Werk der „philosophes“, die es letztlich vermochten, die Grundfesten der Gesellschaft zu unterminieren und damit diese Gesellschaft des Ancien Régime zum Einsturz zu bringen. Zweitens ist der Einsturz des gesamten kolonialen Gebäudes - die erste Bedingung einmal vorausgesetzt - zumindest mit Blick auf Saint-Domingue eine nicht weniger unmittelbare Folge der Arbeit dieser „philosophes“, die sich massiv für die Abschaffung der Sklaverei einsetzten und der Sklaverei jeglichen Boden unter den kolonialwirtschaftlichen Füßen entzogen. Diese doppelte Verbindung besagt im Grunde, dass die Arbeit der insbesondere französischen Philosophen der Aufklärung eine Staat und Kolonialsystem zersetzende und für Frankreich höchst schädliche Aktivität war. Deren Folgen galt es nun zurückzudrängen! 
All dies bedeutete, der Philosophie der Aufklärung und dem Wirken der geistigen Kräfte letztlich eine ungeheure Machtfülle zuzusprechen; wären doch sie es dann gewesen, die die Schwarzen gleichsam in den Aufstand und die Revolution getrieben hätten. Die von der Romanfigur aufgemachte Entwicklungsreihe von den allgemeinen „philosophes“ über die noch immer agierenden und agitierenden Philanthropen bis hin zu den ganz spezifischen „Freunden der Schwarzen“ versuchte, die aus Sicht des Ich verdammenswerte historische Abfolge an irgend einem Glied der Kette zu unterbrechen. Die Französische Revolution einschließlich ihrer Phase der „terreur“, an der vor allem die Jakobiner schuld gewesen seien, wurde ebenso den Aufklärern und Intellektuellen avant la lettre angelastet wie die Erscheinungen jenes Sklavenaufstandes von 1791 mit seinen blutigen Massakern auf beiden Seiten, die wir längst als die Haitianische Revolution bezeichnen müssen. Alle Schuld an diesen vom Soldaten grundsätzlich verurteilten Entwicklungen wurde folglich dem französischen Buch- und Geisteswesen angelastet. Und genau auf dieser Ebene kämpfte nun mit der Waffe der Feder der junge, sechzehnjährige Victor Hugo an der Seite von Monarchisten und Konservativen wie sein Vorbild Chateaubriand.

An dieser Stelle unserer Betrachtungen muss man zweifellos einräumen: Die Attacken gegen die französischen „philosophes“ waren nicht gänzlich aus der Luft gegriffen. Nicht umsonst war einer der großen Bestseller des „Siècle des Lumières“ - Guillaume-Thomas Raynals Histoire philosophique et politique des établissements et du commerce des Européens dans les deux Indes, ein Werk, das erstmals 1770 erschien und in seiner dritten Auflage von 1780 gerade in den Kolonien besonders einflussreich war - wiederholt und äußerst vehement für die Abschaffung der Sklaverei eingetreten. In diesem Zusammenhang möchte ich Ihnen den Sachverhalt anhand einer bald nach ihrem Erscheinen im Jahr 1780 berühmt gewordenen Passage der - wie sie kurzgefasst heißt - Histoire des deux Indes gerne zeigen; einer Passage, die aus der spitzen Feder des Mitstreiters Raynals, Denis Diderot, stammt. Ein gutes Jahrzehnt vor den gewaltigen und gewaltsamen Sklavenaufständen auf Saint-Domingue wurde hier eine Art Prophezeiung dessen entwickelt, was sich wenige Jahre später dann in der Tat in der französischen Kolonie abspielen sollte. Aber überzeugen Sie sich selbst! Die Philosophie tut bei Diderot freilich ganz unschuldig so, als spielte sie lediglich den Bauchredner für die Natur:

Eure Sklaven brauchen weder Eure Großzügigkeit noch Eure Ratschläge, um das gotteslästerliche Joch zu brechen, welches sie unterdrückt. Die Natur spricht lauter als die Philosophie \& das Interesse. Schon haben sich zwei Kolonien flüchtiger Neger etabliert, welche Verträge \& Gewalt vor Euren Attentaten schützen. Dieses Leuchten kündigt den Blitzeinschlag an, \& es fehlt den Negern nur noch ein Chef, der mutig genug wäre, sie zu Rachetaten \& zu Massakern zu führen. 


\begin{abstract}
Wo ist er, dieser große Mann, den die Natur ihren verletzten, unterdrückten, verstörten Kindern schuldig ist? Wo ist er? Er wird erscheinen, zweifeln wir nicht daran, er wird sich zeigen, er wird die heilige Standarte der Freiheit erheben. Dieses verehrungswürdige Signal wird die Gefährten seines Unglücks um ihn her versammeln. Stürmischer noch als Sturzbäche werden sie überall die unverlöschlichen Spuren ihres gerechten Hasses hinterlassen. Spanier, Portugiesen, Engländer, Franzosen, Holländer, all ihre Tyrannen werden zur Beute ihres Eisens \& ihrer Flammen werden. Die Felder Amerikas werden trunken sein von diesen Gefühlsbewegungen und einem Blute, welches sie seit so langer Zeit erwarteten, und die Knochen so vieler Unglücklicher, die sich seit drei Jahrhunderten aufhäuften, werden vor Freude erbeben. Die Alte Welt wird ihre Beifallsstürme mit der Neuen Welt verbinden. Überall wird man den Namen des Helden segnen, der die Rechte des Menschengeschlechts wieder in Kraft setzte, überall wird man seinem Ruhme Trophäen errichten. Dann wird der code noir verschwinden; \& der code blanc wird schrecklich sein, wenn der Sieger nur das Recht der Repressalien achtet!

Während sie auf diese Revolution warten, ächzen die Neger unter dem Joch ihrer Arbeiten, deren Gemälde uns nur mehr und mehr für ihr Schicksal zu interessieren vermag. ${ }^{10}$
\end{abstract}

Aus heutiger Sicht ist es faszinierend zu sehen, in welchem Maße in dieser Passage auf Grund zum Teil völlig falscher Annahmen Raynal und mehr noch Diderot - denn Raynal war eher reformerisch orientiert und verdiente indirekt selbst noch am Sklavenhandel - eine künftige und bald schon bevorstehende Revolution ankündigten, die sich in der Tat wenige Jahre später ereignen sollte. Es fehlte tatsächlich nur noch ein geeigneter Anführer. Das Faszinierende der Haitianischen Revolution wird gerade darin bestehen, eine Vielzahl wirklich herausragender Revolutionsführer hervorgebracht zu haben. Freilich wurden sie allesamt rasch von der Revolution wieder gefressen und verdaut: an erster Stelle der in Bug-Jargal erwähnte Boukman selbst, ein Schicksal, das jedoch auch ToussaintL'Ouverture, Dessalines und viele andere betraf.

Zweifellos bestimmten die Vorgänge im Mutterland ganz wesentlich mit, welche Denk- und Handlungsmöglichkeiten in Haiti an der Tagesordnung waren. Denn derartige Sätze, wie wir sie gerade gelesen haben, bildeten einen „discours incendiaire", eine entflammende Rhetorik, die in der Tat vieles in Brand zu stecken vermochte. Das, was zuvor nicht einmal denkbar schien, war nun nicht nur definitiv vorstellbar, sondern auch schreibbar und vor allem publizierbar geworden. Damit aber wurde es lesbar und konnte in die gesellschaftliche Wirklichkeit überführt werden. Wir wissen heute aus einer Fülle von Rezeptionsstudien, dass Raynals Kolonialgeschichte der europäischen Expansion sich nicht nur im Mutterland, sondern gerade auch in den Kolonien bestens verkaufte, auch wenn es sicherlich nicht die schwarzen Sklaven waren, die zur Histoire des deux

10 Raynal, Guillaume-Thomas: Histoire des deux Indes. Vol. 6, Livre 11. Genf: Pellet 1781, S. 134 f. 
Indes einen direkten Zugang hatten. Aber das Geschriebene und Veröffentlichte wurde nun auch für die französischen Pflanzer denkbar; und dieses denkbar Gewordene wurde für sie wie in einem Albtraum schon wenige Jahre später nicht nur zum Lebbaren, sondern zum selbst vor Ort Erlebten. Die Haitianische Revolution besitzt einen Teil ihrer Wurzeln zweifellos in Frankreich und seinem regen Geistesleben: Da hat die Romanfigur Victor Hugos ohne jede Frage Recht.

Der jugendliche Verfasser von Bug-Jargal selbst stand in jenen Jahren ebenso der Französischen Revolution - und vor allem den Jakobinern - wie auch den revolutionären Ereignissen in den Kolonien klar ablehnend und skeptisch gegenüber. In der Forschungsliteratur ist daher - zum Teil sicherlich berechtigt - von einem reaktionären Bild die Rede, das Hugos Sichtweise Haitis und seiner Revolution charakterisiert und geprägt habe. Für den jugendlichen Tausendsassa, der sich an Chateaubriand orientierte, waren es vor allem die Jakobiner, welche die Französische wie die haitianische Revolution mit ihrer ideologischen Verbissenheit in den Ruin, den Zusammenbruch geführt hatten.

Daher wirkt Victor Hugos Roman Bug-Jargal wie eine Art Replik des konservativen, ja reaktionären Schriftstellers auf das Freiheitsversprechen der französischen Aufklärer und „philosophes“ an die Adresse der Sklaven. Denn diese Sklaven erscheinen bei Victor Hugo zwar sehr wohl als Unterdrückte, als zum Teil unmenschlich Ausgebeutete und Gepeinigte; doch verkörpern sie - von der Titelfigur einmal abgesehen - keineswegs eine glücklichere, freiere Zukunft, sondern den Sieg einer noch grausameren und dabei gänzlich dumpfen, dunklen Barbarei. Mit dem Triumph der Sklaven, die sich von der Willkür ihrer Herren befreien, ist in den Augen Hugos kein Versprechen auf die Zukunft verbunden, sondern ein Adieu an die Adresse christlich-abendländischer Zivilisation.

Eines der besten Beispiele für diese Grundüberzeugungen des jungen Hugo ist das Zusammenspiel zwischen Habibrah und Biassou. Habibrah ist ein Zwerg, der einst der Belustigung des an portugiesische Sitten der Hofhaltung gewöhnten Onkels des Erzählers diente und von diesem zwar bevorzugt, aber gleichwohl nicht als vollwertiger Mensch behandelt wurde. Er hat seinen Herrn auf grausame Art ermordet, das Dach über ihm angezündet, die Familie massakriert und ist dann zum Obi geworden - zum Geistlichen und Hexer des Revolutionsheeres. Dieses große Heer schwarzer Sklaven steht mittlerweile - nach dem Tod von Boukman - unter dem Oberbefehl von Biassou, den Hugo wie Boukman selbstverständlich nur aus seinen Lektüren kannte.

Anders als Habibrah ist Biassou wiederum eine historische Gestalt, an der Victor Hugo jedoch nicht weniger die Grausamkeit und Barbarei der Aufständischen aufzuzeigen versucht. Biassou erscheint im Roman als geschickter, seinen Mitstreitern überlegener Kriegsherr, bei dem sich Durchtriebenheit und Grausamkeit die Waage halten. Doch er sticht von der Unordnung, der Anarchie und 
vom Chaos seiner insgesamt als dumm und kulturlos charakterisierten schwarzen Truppen völlig ab. Werfen wir einen Blick auf das vorüberziehende Heer Biassous:

\begin{abstract}
Über all diesen Köpfen flatterten Fahnen in allen möglichen Farben und Devisen, weiß, rot, dreifarbig, mit der königlichen Lilie, über denen die phrygische Mütze der Freiheit schwebte und eine Inschrift geschrieben stand: Tod den Priestern und Aristokraten! - Es lebe die Religion! - Freiheit! - Gleichheit! - Es lebe der König! - Nieder mit dem Mutterland! - Viva España! - Keine Tyrannen mehr! usw. Das Durcheinander war frappierend und zeigte an, dass alle Kräfte der Rebellen nichts als ein Haufen von Mitteln ohne Ziel waren und dass es in dieser Armee nicht weniger Unordnung in den Ideen als unter den Menschen gab.

[...]

Dieser Strom an Barbaren und Wilden zog schließlich vorbei. ${ }^{11}$
\end{abstract}

Damit wird deutlich, dass uns der allwissende Erzähler die aufständischen Sklaven schlicht als ungebildetes und wildes Barbarenheer zu präsentieren versucht, das aus Rebellen besteht, die für Worthülsen und sinnlose Ziele kämpfen, von deren Verwirklichung und deren Folgen sie keinerlei Ahnung und Vorstellung haben: Sie sind nichts als die Verkörperung schierer Gewalt und Brutalität. Doch die französische Kolonie ist gleichsam eine ferne Echokammer, welche die Lautquellen der Metropole, des französischen Mutterlandes, gleichsam umkodiert und völlig anders wieder zurückwirft. Wir vernehmen uns sattsam bekannte Kampfesrufe, die an den Rändern des Reiches jedoch nur noch sinnentleert ausgestoßen werden und die geistige Verwirrung der Aufständischen vorführen. Diese erscheinen wie Automaten, die vorprogrammierte, aber ihnen unklare und unverständliche Bewegungen ausführen, ohne dabei zu wissen, wohin die gesamte Reise gehen wird.

Wir stoßen hier erneut auf jene Dialektik des Kolonialen, die uns bereits bei Virginie in Bernardin de Saint-Pierres Roman begegnet war, insoweit es gerade die fremden, im französischen Mutterland kursierenden (Bildungs-) Vorstellungen waren, die sie unterdrückten und ihr doch zugleich auch die Möglichkeit gaben, daraus ein potentielles Instrument der Selbstbefreiung zu machen. Mir scheint, dass Hugos Roman gleichsam unterhalb der expliziten ideologischen (und als reaktionär zu bezeichnenden) Position eben diese Dialektik doch sehr gut mittransportiert und zum Ausdruck bringt. Es ist gerade die Verballhornung der Ideale der Revolution, die letztlich deutlich macht, dass Saint-Domingue nicht einfach von Frankreich abzutrennen und loszulösen ist, sondern durch eine komplexe Bindung mit dem Mutterland verbunden ist und bleiben wird. Dies - so ließe sich aus gegenwärtiger Perspektive sagen - ist bei aller historischen Distanz

11 Hugo, Victor: Bug-Jargal, S. $169 \mathrm{f}$. 
bis heute der Fall. Denn die unverbrüchliche und zugleich gegensätzliche Verbindung mit der „Métropole“ ist eine Grundkonstante haitianischer Literatur und Kultur, welche nicht allein durch Phasen des Exils und der Flucht nach Frankreich, sondern auch durch das Französische als Literatursprache stets eine komplexe, widersprüchliche Dimension beinhaltete.

Ich kann an dieser Stelle nicht auf die zahlreichen Einsprengsel aus anderen Sprachen eingehen, die wir in Bug-Jargal vorfinden. Diese betreffen zum einen das Spanische, das in der noch immer spanischen Kolonie Santo Domingo gesprochen wurde - und das Victor Hugo in seiner Kindheit in Madrid kennengelernt hatte -, aber auch das Kreolische, das „français créole“, das ebenfalls immer wieder in Bruchstücken auftaucht. Insofern bekommt die interne Relationalität monolingualen Zuschnitts hier durchaus aus Sicht des Mutterlandes Frankreich bezüglich der ausschließlichen Beschränkung auf das Französische erste signifikante Risse.

In diesem Zusammenhang müssen wir noch einmal zum Bild der Schwarzen in diesem Roman über die erste Phase der Haitianischen Revolution zurückkehren. Denn unser Eindruck von den Darstellungen im Roman wäre nicht vollständig, würden wir die Sklaven nur als Barbaren und Wilde zeigen. Spätestens seit dem 18. Jahrhundert - aber Vorläufer gehen bis ins 16. Jahrhundert zurück - findet sich gleichsam das Gegenbild zum Barbaren, nämlich der Edle Wilde, der „bon sauvage“, der in nicht geringerem Maße das europäische Imaginäre bevölkerte. ${ }^{12}$

Eben dieses Bild des Edlen Wilden aber gibt Bug-Jargal selbst ab, der Titelheld des Romans, wobei er auf höchst hingebungsvolle Weise die dem weißen Léopold versprochene Marie alias María liebt. Er ist dem Weißen von Beginn an in vielerlei Hinsicht körperlich wie seelisch überlegen. Zunächst einmal ist er physisch stärker. Denn es gelingt ihm mühelos, den Ich-Erzähler niederzudrücken und in Schach zu halten; und es wäre ein leichtes für ihn gewesen, ihm den Garaus zu machen und den unliebsamen Rivalen in der Liebe zu Marie aus der Welt zu schaffen. Damit ist dieser schöne junge Mann, der in seinem Herkunftsland in

12 Vgl. hierzu u. a. Graf, Marga: Der „Edle Wilde“ bei Chateaubriand und José de Alencar - Hintergründe und Einflüsse zum Motiv des „homme de la nature“ in der Literatur des 19. Jahrhunderts in Frankreich und Brasilien. In: Lüsebrink, Hans-Jürgen / Siepe, Hans Theo (Hg.): Romanistische Komparatistik. Begegnungen der Texte - Literatur im Vergleich. Frankfurt am Main - Berlin - Bern: Peter Lang 1993, S. 195-214; Jurt, Joseph: Die Kannibalen. Europäische Bilder der Indianer - von Kolumbus bis Montaigne. In: Fludernik, Monika / Haslinger, Peter / Kaufmann, Stefan (Hg.): Der Alteritätsdiskurs des Edlen Wilden. Würzburg: Ergon Verlag 2002, S. 45-63; sowie Kohl, KarlHeinz: Entzauberter Blick. Das Bild vom Guten Wilden und die Erfahrung der Zivilisation. Berlin Frankfurt am Main: Verlag Medusa 1981. 
Afrika einst ein Königssohn und König war, zugleich auch ein Herkules, wie dies an mehreren Stellen des Romans explizit betont und hervorgehoben wird.

Aber dieser schwarze Herkules ist ganz anders gebaut als seine abendländischen Vorbilder in der Abfolge mythologischer Gestalten. Der Mythos verbindet den Schwarzen, der aus Afrika in die Karibik deportiert wurde, über die Säulen des Herkules mit Gibraltar, eine Ortsbezeichnung, die gleich zu Anfang des Romans in die Semantik des Romangeschehens eingeblendet wird. Ich möchte Ihnen gerne zeigen, wie dieser herkulische junge Mann - der wenige Seiten zuvor Maria vor einem schrecklichen Krokodil, das sie beißen will, gerettet hatte - in kultureller und politischer Hinsicht in dem nach ihm benannten Roman entworfen wird. Dazu muss ich eine Abfolge von breiter ausgeführten Passagen, die unmittelbar aufeinander folgen, im nächsten Zitat etwas zusammenstauchen. Vergessen wir dabei nicht: Der Ich-Erzähler verdankt Bug-Jargal immerhin das Weiterleben seiner geliebten Braut, welche dieser schwarze Herkules vor dem sicheren Tod bewahrte! So versucht er, mit dem plötzlich von tiefer Melancholie ergriffenen jungen Mann ins Gespräch zu kommen:

Als ich mit ihm plauderte, bemerkte ich, dass er mit Leichtigkeit des Französischen wie des Spanischen mächtig war und dass sein Geist nicht der Kultur zu entbehren schien; er kannte spanische Romances, welche er ausdrucksvoll sang. Dieser Mann war aus so vielen Blickwinkeln heraus so unerklärlich, dass mir bis zu diesem Zeitpunkt die Reinheit seiner Sprache nicht aufgefallen war. [...]

Als ich nahe an den Hütten unserer Schwarzen vorbeikam, war ich von der außerordentlichen Aufregung überrascht, die dort allenthalben herrschte. Die meisten waren noch wach und sprachen mit der größten Lebendigkeit. Ein bizarrer Name, Bug-Jargal, ward mit Ehrerbietung ausgesprochen und tauchte häufig inmitten ihres unverständlichen Geschwätzes auf. Ich verstand dennoch einige Worte, deren Sinn mir darin zu bestehen schien, dass sich die Schwarzen der Ebene im Norden in vollständiger Revolte befanden und ebenso die Bewohner wie die Plantagen, welche auf der anderen Seite des Kaps lagen, den Flammen übergaben. ${ }^{13}$

Der Ich-Erzähler ist von Bug-Jargal beeindruckt; doch seine Beschreibungskategorien verraten nur allzu deutlich, dass er seine Reflexionen über den unerklärlichen jungen Mann nicht auf den Punkt zu bringen vermag. Wer ist dieser afrikanische Königssohn und was führt er im Schilde? Woher hat er all seine Kenntnisse? Im Grunde versteht Léopold Bug-Jargals Kultur nicht, weiß nichts von dessen Welt, ja kann sich keinen Reim darauf machen, warum er über solche Fähigkeiten verfügt. $\mathrm{Zu}$ sehr ist Léopold noch immer in seinen rassistischen und kolonialistischen Vorurteilen gefangen. Überhaupt ist der Begriff „culture“ im Diskurs des jungen

13 Hugo, Victor: Bug-Jargal, S. 52 u. 59. 
Weißen ganz eindeutig reserviert für den abendländischen, den west- und südeuropäischen Raum der Romania unter Einschluss des Bereichs des Spanischen und Französischen. Für Léopold ist er nicht auf Afrika selbst anwendbar: Hugo führt schön die vom Rassismus diktierten Begrenztheiten seiner Romanfigur vor. Allein im Abendland ist die ,eigentliche' Kultur angesiedelt. Erst dadurch, dass Bug-Jargal sowohl über das Französische wie auch das Spanische verfügt und beide europäischen Sprachen tadellos beherrscht, kann er für Léopold zu jener Figur werden, der menschliche Größe zukommt. Erst so wird für den jungen Franzosen der Edelmut des schwarzen Herkules verständlich, ein Edelmut, der im Verlauf des Romans immer deutlicher hervortritt und Bug-Jargal zu einem Edlen Wilden macht, der freilich im Körper eines Wilden und Barbaren gefangen ist. Daher wohl auch die auffällige Melancholie dieser Titelfigur.

Mit der zweiten Hälfte des obigen Zitats ist der 22. August 1791 gekommen: der Tag der geplanten Heirat und zugleich der Tag des großen Aufstands der schwarzen Sklaven gegen ihre weißen Herren, ein Aufstand, dessen Führer historisch gesehen Boukman und romanintern betrachtet Bug-Jargal ist. Denn selbstverständlich steht dieser Herkules auf Seiten der schwarzen Sklaven. Rasch wird deutlich, dass er von der schwarzen Sklavenbevölkerung der Insel längst verehrt und mit großem Respekt behandelt wird. Er ist in den Formulierungen Diderots in Raynals Histoire des deux Indes der große Chef, der sich - wie vom Philosophen vorhergesagt - an die Spitze eines Aufstandes setzen wird, der rasch zu einer Revolution geraten sollte.

Gegen Bug-Jargals Sprachfähigkeiten im Französischen wie im Spanischen wird der ,jargon“ der schwarzen Sklaven abgesetzt, der für französische Ohren unverständlich ist und nicht als Sprache anerkannt wird. Das „français créole“ war für die französischen Kolonialherren - anders als für die heutige Linguistik keine wirkliche Sprache. Diese komplexe kulturelle und sprachliche Situation führt uns deutlich vor Augen, dass Bug-Jargal sozusagen zwischen zwei Welten und drei Kulturkreisen steht: Denn er versteht perfekt das Französische und Spanische, das er wunderbar spricht und singt. Er versteht aber auch die afrikanischen Sprachen seiner eigentlichen Herkunft sowie den ,jargon inintelligible“ von Saint-Domingue, dem Léopold nur entnehmen kann, dass ein großer Aufstand bereits losgebrochen sei.

So avanciert Bug-Jargal zu jener Figur, die sich frei zwischen den Kulturen und Sprachen bewegt und als einzige die Möglichkeit besitzt, zwischen Europa, Afrika und Amerika zu vermitteln. Bug-Jargal könnte damit eben jene Transferleistung erbringen, die notwendig gewesen wäre, um ein Blutbad in der französischen Kolonie noch zu verhindern. Doch dies misslingt ihm ebenso wie eine Heirat mit Marie: In diesem Nicht-zueinander-Kommen der beiden Hautfarben und Geschlechter ist die ganze Tragödie der Haitianischen Revolution bereits 
angelegt. In der scheiternden Geschlechterbeziehung zeigt der junge, noch unerfahrene, aber doch visionäre Schriftsteller Victor Hugo auf ein Muster, das als Allegorese das gesamte 19. Jahrhundert im angespannten Verhältnis zwischen beiden Seiten des Atlantiks, aber auch im lateinamerikanischen Nationenbildungsprozess dominieren wird.

Es gehört sicherlich zu den großen literarischen Verdiensten des Romans, dass uns Bug-Jargal auf eine sehr überzeugende Weise begreifen lässt, wie eingeschränkt die Sichtweise auf die außereuropäischen Kulturen - die überhaupt nicht als Kulturen verstanden wurden - zu diesem historischen Zeitpunkt noch war. Erst im Übergang zum 20. Jahrhundert sollten auch in der Wissenschaft dann endlich jene Voraussetzungen dafür geschaffen werden, dass die afrikanischen Kulturen und ihre amerikanischen Weiterentwicklungen auf einer breiteren anthropologischen Basis verstanden werden konnten. Brechen wir an dieser Stelle also unsere Lektüre von Hugos Bug-Jargal ab, dessen Handlungsverlauf angesichts der Ihnen vorgestellten Konstellationen nichts Überraschendes mehr birgt und uns nichts Neues für unser Studium des Verhältnisses zwischen beiden Welten lehren kann! Wir fügen an dieser Stelle einen Exkurs ein, der uns auf unserem Weg zum anderen Ufer des Atlantiks eine Reihe von Einsichten vermitteln soll, die wir dann für unsere Analysen von Texten aus Lateinamerika dringend benötigen. Gestatten Sie mir also eine kurze Digression, die uns zu einem Autor des 20. Jahrhunderts führen soll, bevor wir uns danach dem 19. Jahrhundert in den Amerikas zuwenden! 